\title{
BMJ Open Self-perceived health status following aneurysmal subarachnoid haemorrhage: a cohort study
}

\author{
Audrey C Quinn, ${ }^{1}$ Deepti Bhargava, ${ }^{2}$ Yahia Z Al-Tamimi, ${ }^{3}$ Matthew J Clark, ${ }^{1}$ \\ Stuart A Ross, ${ }^{4}$ Alan Tennant ${ }^{5}$
}

To cite: Quinn AC, Bhargava D, Al-Tamimi YZ, et al. Self-perceived health status following aneurysmal subarachnoid haemorrhage: a cohort study. BMJ Open 2014;4:e003932.

doi:10.1136/bmjopen-2013003932

- Prepublication history for this paper is available online. To view these files please visit the journal online (http://dx.doi.org/10.1136/ bmjopen-2013-003932).

Received 31 August 2013 Revised 7 February 2014 Accepted 10 February 2014

CrossMark

For numbered affiliations see end of article.

Correspondence to Dr Audrey C Quinn; a.c.quinn@leeds.ac.uk

\section{ABSTRACT}

Objective: The objective of the study was to assess the long-term self-reported health status and quality of life (QoL) of patients following an aneurysmal subarachnoid haemorrhage (ASAH) using a selfcompleted questionnaire booklet.

Design: A two-cohort study.

Setting: A regional tertiary neurosurgical centre. Participants: 2 cohorts of patients with ASAH treated between 1998 and 2008 and followed up at approximately 1 year.

Interventions: Routine care.

Primary and secondary outcomes: A range of standardised scales included: AKC Short Sentences Test, the Barthel Index, the Self-Report Dysexecutive Questionnaire, the Everyday Memory Questionnaire, Stroke Symptom Checklist, Wimbledon Self-Report Scale, Modified Rankin Score (MRS) and a new Stroke-QoL. The data from summated scales were fit to the Rasch measurement model to validate the summed score.

Results: 214 patients (48\%) returned the questionnaires; the majority $(76 \%)$ had a World Federation of Neurosurgeons grade of 1 or 2 . The most frequent aneurysm type was that of the anterior communicating artery (28\%) with approximately $90 \%$ of aneurysms of the anterior circulation. Of those previously in full or part-time employment, $48.9 \%$ were unemployed at follow-up. All summated scales satisfied the Rasch measurement model requirements, such that their summed scores were a sufficient statistic. Given this, one-third of patients were noted to have a significant mood disorder and $25 \%$ had significant dysexecutive function. Patients with an MRS of 3, 4 or 5 had significantly worse scores on most outcome measures, but a significant minority of those with a score of zero had failed to return to work and displayed significant mood disorder.

Conclusions: A range of self-reported cognitive and physical deficits have been highlighted in a cohort of patients with ASAH. While the MRS has been shown to provide a reasonable indication of outcome, in routine clinical follow-up it requires supplementation by instruments assessing dysexecutive function, memory and mood.

\section{Strengths and limitations of this study}

- This set of patient-reported outcome measures opens up the possibility of further investigations to assess the detailed biopsychosocial model and to model the direct and indirect effects of impairments and activity limitations on participation (particularly work) and the quality of life.

- The main limitation of this study is the selection bias posed by those patients who have not responded to this questionnaire, although we were able to show that no bias existed for age, gender and Glasgow Coma Score.

- These outcome measures should be repeated on a larger number of patients with aneurysmal subarachnoid haemorrhage for further evaluation.

\section{INTRODUCTION}

Aneurysmal subarachnoid haemorrhage (ASAH) is a devastating form of intracranial haemorrhage with an incidence of 8-10 per 100000 annually. ${ }^{1}$ Thus, in the UK, about 6000 people are admitted to hospital annually with this condition; in 2011-2012, they had a mean age of 60 years, and almost two-thirds were women. Of those who survive, while limitations in physical functioning may be less common, up to $50 \%$ of patients are left with significant cognitive deficits, including deficits in verbal and nonverbal memory, psychomotor speed, executive function and visual-spatial function. ${ }^{2-4}$ Up to $50 \%$ of survivors who were in employment prehaemorrhage do not return to the same level of work. ${ }^{45}$

The most notable change in management of this disease over the past decade has been the conversion of aneurysm clippings to endovascular coil placement by neurointervention radiologists as described in the International Subarachnoid Aneurysm Trial (ISAT) trial. ${ }^{6}$ The relative risk of death or significant disability at 1 year for patients treated with coils was $22.6 \%$ lower than in surgically 
treated patients, an absolute risk reduction of $6.9 \%$. Also, there were improved back-to-work rates following coiling. The study found that, in patients equally suited for both treatment options, endovascular coil treatment produces substantially better patient outcomes than surgery in terms of survival free of disability at 1 year.

In reporting outcomes, the majority of studies and trials have utilised either the Glasgow Outcome Scale or the Modified Rankin Scale to assess outcome. ${ }^{7-9}$ The former is a crude scale of $0-5$ representing a spectrum from death to good outcome. The latter has been shown to give a disproportionate weighting to physical disability, with inadequate sensitivity to detect the subtle cognitive deficits that are apparent following ASAH. ${ }^{10}$ Despite this, the scale has been recently recommended as the preferred outcome measure in acute stroke research. ${ }^{11}$

Some studies have assessed long-term outcome following ASAH, and recent studies have highlighted the importance and need for functional and neuropsychological outcome assessment. ${ }^{12} 13$ In particular, the absence of standardised neuropsychological test batteries has been noted as well as the poor reporting of neuropsychological outcomes as either primary or secondary outcomes. ${ }^{14}$ While there is some indication that the health status of survivors may be affected for a decade, the course of associated long-term physical and cognitive deficits after ASAH is not yet well established, leading to questions about potential impact on longer term quality of life (QoL) and working capacity, as well as current best clinical practices. ${ }^{15}{ }^{16}$ Given this, it would seem imperative that adequate measurement of physical and cognitive deficits should be considered as part of routine follow-up, to facilitate monitoring of outcome and appropriate referral. While neuropsychological test batteries may be the most informative for the latter, they nevertheless generally require specialised training and considerable time to administer. ${ }^{17}$ Consequently, the aim of the current study was to assess self-reported health status and QoL following ASAH by utilising a simple set of patient-reported outcome measures (PROMs). These were selected to cover a range of cognitive, physical and psychological deficits which can be employed without detailed neuropsychological testing or specialist training. The intention was that this would provide insight into the longer term health status and QoL of patients, and the associations between the various components of health status, and between health status and QoL, and thus potentially lay the groundwork for a conditionspecific toolbox of PROMs for ASAH.

\section{METHODS}

Patients gave informed consent at the time of their follow-up appointment following discharge.

\section{Setting and subjects}

Details of patients admitted to a tertiary neurosurgical centre with ASAH were identified and entered onto a database by a senior nurse or doctor on the neurosurgical unit. Data collected include demographic information and clinical information including Glasgow Coma Score on presentation. Using this database, 450 surviving patients were identified who were admitted in two separate periods between September 1998 and May 2008. The second cohort straddled the introduction of the coiling procedure. ${ }^{6}$ A questionnaire booklet containing a range of outcome measures designed to ascertain health status was sent to these patients, followed by a second letter to confirm that the booklets were received and to record the Modified Rankin Score (MRS).

\section{Patient assessment and outcome measures}

The conceptual framework for this study, and the consequent choice of instruments was the WHO International Classification of Impairments, Disability and Handicaps (ICIDH),${ }^{18}$ subsequently updated during the course of the study to the International Classification of Functioning, Disability and Health (ICF). ${ }^{19}$ The concept of QoL in the current study is viewed as external to health status (defined as functioning in ICF terms), and is similar to that expressed graphically in the Wilson and Cleary model, whereby functioning and perceived health are shown to be precursors to QoL. The ICF also adds the potential impact of mediators (such as personal factors) and moderators (such as environmental factors) to the equation. ${ }^{2021}$ Thus, it is important to understand that the current study does not accept the health-related quality of life (HRQoL) position that, for example, the presence of pain or disability represents a diminished QoL. Rather, QoL is seen to be affected by many factors, including personal characteristics such as resilience and self-efficacy, and as a consequence some with significant levels of impairment and activity limitation can still consider their QoL to be good. ${ }^{22}$ The choice of instruments was guided by this conceptual framework from those available at the time, and these were put together into a questionnaire booklet.

The booklet contained the following outcome measures:

AKC Short Sentences Test: A simple 10-point test to confirm that the patient is able to read and understand the booklet. Scores range from 0 to 10 .

The Postal Barthel Index (BI): A 10-item list that assesses various aspects of mobility and activities. ${ }^{23}$ The patient rates their level of independence in each of the activities according to specified criteria. Scores range from 0 to 100 .

The Self-Report Dysexecutive (DEX) Questionnaire: The DEX questionnaire is a standardised self-report measure of behavioural difficulties associated with executive functioning such as impulsivity, inhibition control, monitoring and planning. ${ }^{24}$ Here the patient rates the frequency of difficulties with emotions or personality, motivation, behaviour and cognitive problems on a five-point scale ranging from never to very often. Scores range from 0 to 80 . A single domain score for 
the DEX has been supported. ${ }^{25}$ One article has suggested that a range of 19-28 is consistent with moderately DEX functioning that requires identification of the possible causes, and $>28$ indicates an important degree of DEX disorder that would include severe pathologies. ${ }^{26}$

The Everyday Memory Questionnaire (EMQ): A 35-item questionnaire assessing the incidence of memory failures based on different everyday errors. For each of these errors, the patient rates the frequency of these errors ranging from 'never' (score of 0 ) to 'all the time' (score of 4). This has originally been described following head injury. ${ }^{27} 28$ The items are divided into five subscales: speech; measuring reading/writing; faces and places; actions and new things.

Stroke Symptom Checklist (SSC): An informal checklist of 12 common symptoms (including effects of mood, cognition and physical problems) associated with brain injury. These were identified at the time by local clinicians. Patients score a point if symptoms are worse now than prior to their illness. Scores range from 0 to 12.

Wimbledon Self-Report Scale (WSRS): The WSRS was originally standardised on a hospital population with predominantly neurological disorders. ${ }^{29}$ It provides a general appraisal of mood rather than being limited to specific symptoms of anxiety or depression. The patient has to rate the frequency with which 30 emotions occur on a four-point scale ranging from most of the time to not all. Using the original dichotomised scoring system of 1100 , scores of $0-7$ are considered normal, 8-10 are borderline and 11-30 represent clinically significant mood disturbance.

MRS: The MRS has been widely adopted in stroke research as the primary clinical endpoint in most trials. ${ }^{9}$ It is a six-point scale of independence and difficulties with activities of daily living, ranging from needing constant care to complete independence.

A needs-based Stroke-Specific Quality of Life scale (Stroke-QoL) was introduced for cohort $2 .^{30}$ This is a new scale but potentially appropriate for this diagnosis, as some of the original qualitative work was undertaken including those with ASAH. Comprising 30 dichotomous items, a high score represents a poor QoL.

\section{Statistics}

As many of the scales were lacking evidence of validity for SAH at the time of inclusion in the study, the data from all summated scales without evidence of validity for at least stroke, if not SAH, were fit to the Rasch measurement model to ascertain their internal construct validity, and to determine if the summed score was a sufficient statistic for the construct being measured. Briefly, the data were required to satisfy the model expectations about the pattern of responses, as well as to satisfy a number of assumptions, including local dependence and unidimensionality. These manifest as a number of fit statistics, whose ideal values are shown at the foot of the fit table (table 1) below. Where a breach of the local independence assumption was found among item sets, these were summated into testlets (super items) to adjust for the effect on fit, and reliability. ${ }^{31}$ The data were fitted to the Rasch model using the RUMM2030 software, utilising the partial credit model. ${ }^{32} 33$ Full details of the process of Rasch analysis can be found elsewhere. $^{34} 35$

All data were analysed with SPSS V.20. All data from ordinal scales were subjected to appropriate nonparametric statistics. Where logistic regression is reported, all patient-reported outcomes are entered into the models, dichotomised at their median unless explicitly stated otherwise, and used as indicator variables. Only those variables that were significant predictors are reported in the outcome tables.

\section{RESULTS}

\section{Response and characteristics of patients}

Of the 450 booklets sent, $214(47.6 \%)$ complete sets were returned, 97 from cohort 1 and 117 from cohort 2. Analysis of non-response bias showed that there was no significant difference for age $(\mathrm{t}=0.838 ; \mathrm{p}=0.403)$, gender $\left(\chi^{2}\right.$ 0.902; $\left.\mathrm{p}=0.376\right)$ or Glasgow Coma Scale (GCS) on admission ( $\mathrm{t}=0.811 ; \mathrm{p}=0.418)$ between those who did and did not respond.

The mean age of those responding was 56.6 years (SD 10.7 ), of whom $68 \%$ were women. Most patients $(76 \%)$ had presented with the World Federation of Neurosurgeons (WFNS) grade 1 or 2 subarachnoid haemorrhage $(\mathrm{SAH})$. There was no significant difference for age $(t=1.254 ; \mathrm{p}=0.225)$ or gender $\left(\chi^{2} 3.3\right.$; $\mathrm{p}=0.79$ ) by cohort. The most frequently noted aneurysm location was that of the anterior communicating artery. With the introduction of the coil procedure within cohort $2,41.3 \%$ of that cohort had been coiled.

\section{Validity of questionnaires for SAH}

Data from five questionnaires, without previous evidence of internal construct validity for stroke and/or SAH, were fit to the Rasch model. All scales showed adequate fit to the model, after some adjustments for local dependencies among the item sets (table 1). Consequently, the summed score of each scale can be considered a sufficient statistic for the trait being measured. Where the total item set is shown to fit the Rasch model, all subsets of items will do so (eg, subscales). ${ }^{36}$

\section{Health status}

Given this, table 2 shows the responses to the various questionnaires, including the median and IQR for each scale. At follow-up, over four in five $(82.6 \%)$ were $0-2$ on the modified self-reported Rankin Scale, and there was no significant difference between cohorts $\left(\chi^{2} 2.20\right.$; $\mathrm{p}=0.821)$. The response to the AKC Short Sentences Test indicated that the majority of those who responded to the follow-up were able to read and understand the booklet. Nine of $10(91 \%)$ scored a maximum on the 
Table 1 Rasch analysis

\begin{tabular}{|c|c|c|c|c|c|c|c|c|c|c|c|c|}
\hline & \multirow[b]{2}{*}{ Description } & \multirow[b]{2}{*}{$\chi^{2}$} & \multirow[b]{2}{*}{ df } & \multirow[b]{2}{*}{ p Value } & \multicolumn{2}{|c|}{$\begin{array}{l}\text { Residual } \\
\text { item }\end{array}$} & \multicolumn{2}{|c|}{$\begin{array}{l}\text { Residual } \\
\text { person }\end{array}$} & \multirow[b]{2}{*}{ PSI reliability } & \multirow{2}{*}{$\begin{array}{l}\text { Percentage } \\
\text { of tests }>5 \%\end{array}$} & \multirow[b]{2}{*}{$95 \% \mathrm{Cl}$} & \multirow[b]{2}{*}{$\mathbf{N}$} \\
\hline & & & & & Mean & SD & Mean & SD & & & & \\
\hline 1 & DEX & 63.5 & 40 & 0.011 & -0.17 & 1.28 & -0.28 & 1.25 & 0.89 & 6.67 & 3.7 to 9.6 & 184 \\
\hline 2 & Everyday Memory & 10.5 & 10 & 0.401 & -0.02 & 1.15 & -0.33 & 0.91 & 0.89 & 6.67 & 3.7 to 9.6 & 200 \\
\hline 3 & Wimbledon & 6.07 & 4 & 0.194 & -0.13 & 0.78 & -0.48 & 0.80 & 0.81 & 2.55 & 0.5 to 5.6 & 196 \\
\hline 4 & Symptom Checklist & 36.89 & 24 & 0.045 & 0.07 & 1.41 & 0.20 & 0.75 & 0.75 & 3.72 & 0.1 to 6.88 & 188 \\
\hline \multirow[t]{2}{*}{5} & Stroke QoL & 6.91 & 4 & 0.141 & -0.18 & 0.92 & -0.35 & 1.04 & 0.74 & 2.00 & 02.3 to 6.3 & 100 \\
\hline & Ideal values & & & $>0.05^{\star}$ & & $<1.4$ & & $<1.4$ & $>0.70$ & $<5.0$ & $L C l<5.0$ & \\
\hline
\end{tabular}

${ }^{*}$ Bonferroni adjusted.

DEX, Self-Report Dysexecutive Questionnaire; LCl, lower confidence interval; QoL, quality of life.

test, with only 6 patients $(2.9 \%)$ scoring 7 or $8 / 10$. The majority of those responding also had a maximum, or near maximum, score on the BI with just 20 patients $(12.5 \%)$ scoring below 80, suggesting, as did the Rankin Scale, that there was little residual physical dependency. Despite this, a median of seven symptoms were reported from the Stroke Symptom Checklist. Less than one in five $(19.2 \%)$ reported no symptoms, while the most common symptom reported was irritability $(57.9 \%)$, followed by anxiety $(57.5 \%)$. Other symptoms such as headaches or blurred vision were reported by approximately half of the patients.

The extent of DEX function indicated that while most patients displayed few signs of impairment of this function, there was a minority who did so (figure 1 ). With a median score of 12, the upper quartile was 26. Likewise, problems with everyday memory were absent for the majority, although a significant minority displayed some impairment associated with speech. A third (33\%) displayed borderline/caseness for significant mood disorder on the Wimbledon scale. This was strongly associated with an MRS of 3 or more, with $44.5 \%$ showing borderline/caseness, compared to just $17 \%$ of those with a score of less than $3\left(\chi^{2} 16.91 ; \mathrm{p}<0.001\right)$. All the scales showed a significant gradient across the MRS groups with the exception of the SSC (table 3). Likewise, most scales showed strong bivariate (Spearman) correlations with one another (table 4).

Two-thirds $(66.8 \%)$ of those responding were in work previously, but only one-third $(33.1 \%)$ were at follow-up. Thus, of those previously in full-time or part-time employment, $47 \%$ were unemployed at follow-up. Of those with an MRS of zero, $32.8 \%$ had failed to return to work; of those with an MRS of $1-2,52.2 \%$ had failed to return to work, and of those with an MRS of 3+, $100 \%$ had failed to return to work.

Several factors had strong associations with return to work with this previously employed group. For example, those returning to work were significantly younger at 51 years than those who did not return, at 56.7 years $(\mathrm{t}=4.091 ; \mathrm{p}<0.001)$. One half $(50.78 \%)$ of those not returning to work were borderline or case for mood disorder, compared to just less than one in six $(15.7 \%)$ of those who had returned to work $\left(\chi^{2} 19.05 ; \mathrm{p}<0.001\right)$. To complete the picture, just one patient $(1.3 \%)$ not previously in work reported full-time employment at follow-up. A backwards logistic regression was undertaken to identify those factors, which appear to be

Table 2 Median and IQR of health status instruments

\begin{tabular}{|c|c|c|c|c|c|}
\hline Scale & Minimum & Maximum & Median & IQR & $\mathrm{N}$ \\
\hline Rankin & 0 & 5 & 1 & $0-2$ & 178 \\
\hline AKC & 7 & 10 & 10 & $10-10$ & 206 \\
\hline Barthel Index & 27 & 100 & 100 & $95-100$ & 160 \\
\hline Stroke Symptom Checklist & 0 & 12 & 7 & $3.5-10$ & 189 \\
\hline DEX & 0 & 76 & 12 & $4-26$ & 195 \\
\hline \multicolumn{6}{|l|}{ Everyday Memory } \\
\hline Speech & 0 & 52 & 11 & $4-24$ & 205 \\
\hline Reading & 0 & 16 & 2 & $0-7$ & 208 \\
\hline Face recognition & 0 & 24 & 2 & $1-6$ & 203 \\
\hline Actions & 0 & 24 & 2 & $0-9$ & 209 \\
\hline Learning & 0 & 23 & 4 & $1-9$ & 203 \\
\hline Wimbledon Mood & 0 & 83 & 18.5 & $6-38$ & 196 \\
\hline Stroke-QoL & 0 & 29 & 9.3 & $2.6-17.0$ & $113^{\star}$ \\
\hline
\end{tabular}




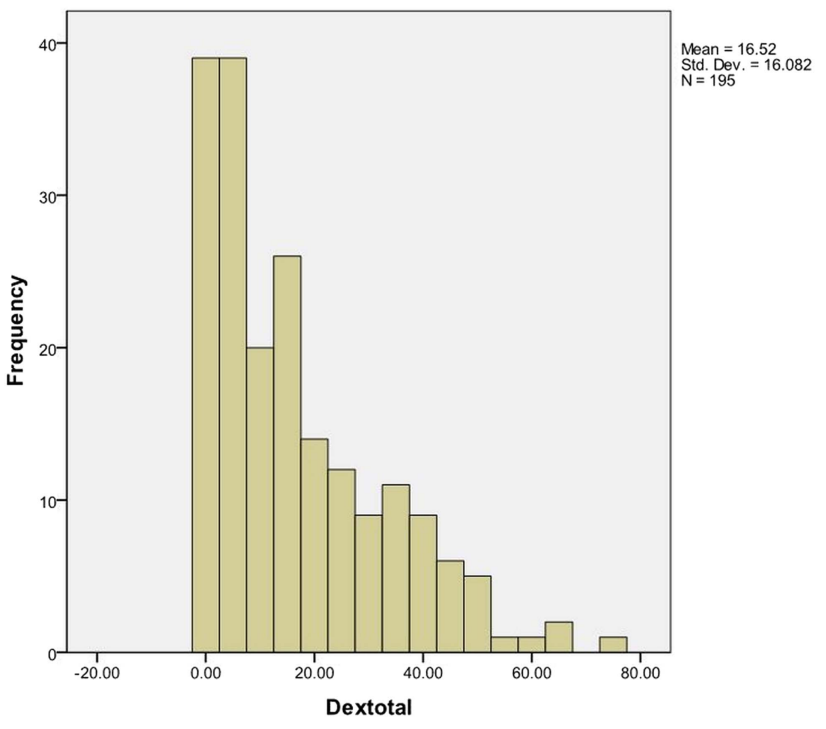

Figure 1 Distribution of Dysexecutive Function Questionnaire Score.

associated with the ability to return to work, having been previously employed. For this group, age was significantly associated with return to work, physical dependency expressed by a BI score of less than 80 , a score of greater than zero on the Rankin Scale and memory deficits associated with speech (table 5). Thus, older people, those with residual physical disability and those experiencing memory problems were less likely to have returned to work. The model is adequate with a Hosmer-Lemeshow Goodness of fit test of 0.244, a Nagelkerke $R^{2}$ of 0.396 and overall correct classification of $73.6 \%$.

In cohort $2(n=117)$ where additional clinical information was obtained, there was no association between Fisher grade and the MRS $\left(\chi^{2} 3.266 ; \mathrm{p}=0.195\right)$. Neither was there any association between Fisher grade and whether or not the patient was clipped or coiled $\left(\chi^{2}\right.$ $0.212 ; \mathrm{p}=0.693)$. Within cohort 2 , where coiling was introduced, almost three in five $(58.7 \%)$ were clipped.
There was no significant difference in age $(\mathrm{t}=0.762$; $\mathrm{p}>0.448)$ and gender $\left(\chi^{2} 2.164 ; \mathrm{p}=0.112\right)$ by type of intervention. Likewise, there was no significant difference in the Fisher grade by intervention $\left(\chi^{2}\right.$ 2.854; $\mathrm{p}=0.415)$ or WFNS level $\left(\chi^{2} 0.601 ; \mathrm{p}=0.438\right)$. Many outcomes also showed no difference by type of intervention, including return to work among those previously employed $\left(\chi^{2}\right.$ 0.061; $\left.\mathrm{p}=0.806\right)$. However, over half $(55.8 \%)$ of those coiled were graded as a Rankin score of zero, compared to just under a third $(32.8 \%)$ of those clipped $\left(\chi^{2} 5.48 ; p=0.027\right)$. Furthermore, patients who had been coiled reported better levels of mood on the Wimbledon Scale (Mann Whitney U; $\mathrm{p}=0.037$ ), and a better QoL on the new Stroke-QoL scale, than those clipped (median 12.7; Mann Whitney $\mathrm{U} ; \mathrm{p}=0.028$ ).

There were also indications of a considerable impact on the ability to meet needs as expressed by the needsbased QoL scale, available in cohort 2 with 117 cases. For example, of those previously working, there was a significantly worse level of QoL for those no longer working (Independent Samples Median test $\mathrm{p}=0.035$ ). Splitting the QoL scale at the median value (9.3), a backwards logistic regression identified that an MRS of three and above is strongly associated with a significantly poorer reported QoL. Likewise, above borderline mood disorder, and scoring in the upper quartile of the DEX function scale, although the latter with only a strong trend (table 6). The model is adequate with a Hosmer-Lemeshow Goodness of fit test significance of 0.214 , a Nagelkerke $\mathbf{R}^{2}$ of 0.606 and overall correct classification of $81.2 \%$.

\section{DISCUSSION}

This study set out to see if a set of PROMs could provide a broad set of information across the impairment-activity limitation-participation and QoL continuum. Sending the booklet followed by one letter of reminder has enabled a return rate approaching $50 \%$. All the chosen scales were shown to have unidimensional valid total

\begin{tabular}{|c|c|c|c|c|c|c|c|}
\hline Scale & $\begin{array}{l}\text { MRS } 0 \\
\text { Median }\end{array}$ & IQR & $\begin{array}{c}\text { MRS 1-2 } \\
\text { Median }\end{array}$ & IQR & $\begin{array}{r}\text { MRS 3+ } \\
\text { Median }\end{array}$ & IQR & $\mathbf{N}$ \\
\hline Barthel Index & 100 & $100-100$ & 100 & $90.5-100$ & 75 & $49.7-90.0$ & 160 \\
\hline Stroke Symptom Checklist & 7 & $2-10$ & 7 & $4.3-9.0$ & 6.5 & $3-9$ & 189 \\
\hline DEX & 6 & $1-13$ & 16 & $5.5-33.0$ & 29 & $17-41$ & 195 \\
\hline \multicolumn{8}{|l|}{ Everyday Memory } \\
\hline Speech & 6 & $2.5-10.5$ & 14.5 & $7.3-27.5$ & 30 & $13.5-38.8$ & 205 \\
\hline Reading & 1 & $0-3$ & 4 & $1-7$ & 7.5 & $3.3-13.8$ & 208 \\
\hline Face recognition & 1 & $0-2$ & 3 & $1-6$ & 7 & $4.5-15.5$ & 203 \\
\hline Actions & 1 & $0-3$ & 4 & $1.0-9.5$ & 11.5 & $5.0-16.8$ & 209 \\
\hline Learning & 3 & $0.5-5.0$ & 6 & $2-10$ & 9.5 & $5-16$ & 203 \\
\hline Wimbledon Mood & 9 & $2.0-18.8$ & 28 & $14-45$ & 39 & $24.8-58.3$ & 196 \\
\hline Stroke-QoL & 3 & $1.0-5.8$ & 14 & $8-20$ & 20 & $15.5-25.2$ & $113^{\star}$ \\
\hline
\end{tabular}


Table 4 Bivariate (Spearman) correlations between patient-reported outcome measures

\begin{tabular}{|c|c|c|c|c|c|c|c|c|c|c|}
\hline & QoL & Dextotal & Barthel & Speech & Reading & Faces & Actions & Learning & SSC & Wimb \\
\hline QoL & 1.000 & & & & & & & & & \\
\hline Dextotal & $0.700^{* \star}$ & 1.000 & & & & & & & & \\
\hline Barthel & $-0.644^{\star \star}$ & $-0.494^{\star \star}$ & 1.000 & & & & & & & \\
\hline Speech & $0.613^{\star *}$ & $0.837^{\star *}$ & $-0.463^{\star *}$ & 1.000 & & & & & & \\
\hline Reading & $0.664^{\star \star}$ & $0.764^{\star \star}$ & $-0.508^{\star *}$ & $0.829^{\star \star}$ & 1.000 & & & & & \\
\hline Faces & $0.648^{\star \star}$ & $0.711^{\star \star}$ & $-0.500^{\star \star}$ & $0.803^{\star \star}$ & $0.781^{\star \star}$ & 1.000 & & & & \\
\hline Actions & $0.616^{\star *}$ & $0.731^{\star *}$ & $-0.436^{\star \star}$ & $0.820^{\star *}$ & $0.754^{\star *}$ & $0.833^{\star *}$ & 1.000 & & & \\
\hline Learning & $0.566^{\star \star}$ & $0.705^{\star \star}$ & $-0.388^{\star *}$ & $0.784^{\star \star}$ & $0.745^{\star \star}$ & $0.816^{\star \star}$ & $0.782^{\star \star}$ & 1.000 & & \\
\hline SSC & $0.668^{\star \star}$ & 0.088 & -0.075 & 0.002 & -0.035 & 0.022 & 0.003 & -0.027 & 1.000 & \\
\hline Wimb & $0.711^{\star \star}$ & $0.746^{\star \star}$ & $-0.441^{\star *}$ & $0.648^{\star \star}$ & $0.611^{\star *}$ & $0.573^{\star *}$ & $0.616^{\star *}$ & $0.540^{* *}$ & 0.050 & 1.000 \\
\hline
\end{tabular}

A high score is worse for all scales other than the Barthel Index. ${ }^{*}$ Significant $<0.01$.

SSC, Stroke Symptom Checklist.

scores through fit to the Rasch measurement model. Scores on the AKC reading test indicated that all patients who returned their questionnaire were capable of understanding the booklet.

Although symptoms were prevalent, the high median BI score indicated that patients required minimal assistance with activities of daily living. In another crosssectional study of 40 survivors with ASAH originally categorised as independent, it was shown that only 5 $(12.5 \%)$ patients scored less than 100 in the BI (range from 70 to 95 in this subgroup). ${ }^{37}$ Nevertheless, $17 \%$ of patients had a poor outcome (3-5) as assessed by the MRS. In addition, one-quarter also displayed significant DEX function. The DEX scores in the current study are comparable to those in another recent study investigating cognitive deficit in a small cohort of clipped and coiled patients with ASAH (mean DEX score 19.4 and 15.4 in clipped and coiled patients, respectively). ${ }^{38}$ The upper quartile of the DEX in this cohort of survivors, and thus one-quarter of the cohort, was close to the level which in one study indicated an important degree of DEX disorder that would include severe pathologies. ${ }^{26}$ Over half of those at this level of DEX function have scored an MRS of 2 or less.

The results of the EMQ demonstrate that patients in general also exhibit some detectable memory deficits, particularly in 'speech', which in the current study has been shown to influence return to work. The results of the WSRS indicate that a substantial minority (33\%) had a clinically relevant mood disorder. This is similar to a study of brain injury patients utilising the WSRS, in

Table 5 Backwards logistic regression predicting return to work

\begin{tabular}{lllll}
\hline & $\boldsymbol{\beta}$ & Exp & Cl & \multicolumn{1}{l}{ Sig. } \\
\hline Age & -0.116 & 0.891 & 0.840 to 0.945 & $<0.001$ \\
Barthel Index & -0.965 & 0.381 & 0.158 to 0.918 & 0.032 \\
Speech & -0.715 & 0.489 & 0.312 to 0.767 & 0.002 \\
Rank $(0 ; 1+)$ & -1.155 & 0.315 & 0.130 to 0.764 & 0.011 \\
\hline
\end{tabular}

Exp, exponentiation; Sig., significance. which it was demonstrated that $38 \%$ of patients had a clinically significant mood disorder at 6 months post injury, ${ }^{39}$ and $35 \%$ at 1-year post injury. ${ }^{40}$ Other more recent studies have reported high levels of emotional disorders following $\mathrm{SAH}$ and high levels of depression found to be associated with poorer QoL after 1 year. ${ }^{41} 42$ Furthermore, in one study, post-traumatic stress disorder was found in one in four participants 3 years after SAH. $^{43}$

The recently developed needs-based Stroke-QoL measure was shown to fit the Rasch model and to demonstrate a strong gradient across the MRS levels. Given that it measures a different construct to health status, it offers the potential to determine how health status impacts on QoL and, in further studies, examine potential mediating and moderating factors which may be amenable to intervention. The consistent level of correlation (of 0.6-0.7) found between the measure and the other constructs suggest considerable scope for the development of a comprehensive biopsychosocial model with the Stroke-QoL as an endpoint or primary outcome. The needs-based approach to QoL itself is now widely used across many diagnostic groups. ${ }^{44} 45$ The construct, focusing on the impact of the condition on the ability of the person to meet their needs, has previously shown a strong correlation with subjective wellbeing, traditionally the generic measure of QoL. ${ }^{46}$

Almost half of the patients in the current study who were previously employed were unemployed at follow-up. In a recent Australian study, two-thirds of patients who

Table 6 Backwards logistic regression for predicting poor quality of life (>median)

\begin{tabular}{llrll}
\hline & $\boldsymbol{\beta}$ & \multicolumn{1}{c}{ Exp } & Cl & Sig. \\
\hline MRS $>3$ & 3.952 & 52.04 & 5.5 to 492.3 & 0.001 \\
Mood borderline/case & 1.194 & 3.30 & 1.08 to 10.1 & 0.037 \\
$\begin{array}{l}\text { Dis-exec function } \\
\text { upper quartile }\end{array}$ & 0.943 & 2.57 & 0.768 to 8.58 & 0.126 \\
\hline
\end{tabular}

Exp, exponentiation; MRS, Modified Rankin Score;

Sig., significance. 
were in prehaemorrhage employment returned to full-wage employment at 1 year following haemorrhage. ${ }^{47}$ This was noted to be higher than previously reported $^{48} 49$ and much higher than the employment level noted in the current study. We did not specifically ask about why our patients did not return to work and accept that this could have been out of choice or if the patient was at or near retirement age. However, it is important to note that only $3.5 \%$ of those working prior to their ASAH were above retirement age at the time, and half were below 55 years of age.

The main limitation of this study is the selection bias posed by those patients who have not responded to this questionnaire, although we were able to show that no bias existed for age, gender and GCS level. Nevertheless, it is possible that those who, for example, would have scored much lower on the AKC Short Sentences Test, indicating problems understanding the questions, chose not to respond. If this were the case, then the study would understate the true impact of the ASAH on peoples' lives. By design, the study relied on selfcompletion of standardised instruments, as opposed to objective structured clinical tests. Thus, it relies on previous validation of those instruments, supported by the Rasch analysis in the current study, which suggests their appropriateness for an ASAH sample. However, these outcome measures should be repeated on a larger number of patients with ASAH for further evaluation. This is particularly the case for the Stroke-QoL which, as yet, awaits full validation, although the current study, with fit to the Rasch model and good correlations with a range of comparator measures, provides evidence for the scale in this diagnostic group.

In the current study, a large proportion of patients had a good (0-2) MRS at follow-up. Results from the ISAT demonstrated that at 1-year follow-up, $69.1 \%$ and $76.5 \%$ of patients in the surgical and endovascular groups, respectively, had an MRS of $0-2 .{ }^{6}$ With $82 \%$ achieving this grade in the current study, MRSs are better than those demonstrated in the ISAT study for patients in the surgical arm. This may be secondary to a longer follow-up for some patients in this study (range of up to 400 days follow-up and therefore continued improvement noted after 1 year). This may also be due to the effects of a single centre with specialist experience at offering predominantly surgical aneurysm treatment.

In the light of current recommendations for acute stroke trials, in the context of longer term follow-up, we have shown that an MRS score of 0 (no symptoms at all) does not correlate with a complete recovery, and thus does not tell the full story. Almost a third of those graded zero had been unable to return to work, and one in six were classified as having borderline/caseness for mood disorder. With the recent changes in management of ASAH, namely to an endovascular service, we routinely review all patients early (at 2-3 months) and again at a year post coiling. This provides us with an opportunity to assess early and later outcomes, particularly memory impairment, cognition and mood disorders and also those factors shown to be associated with failure to return to work, and with reported poorer QoL. In this respect, some measures of memory impairment and mood disorder would seem to be appropriate in addition to the MRS.

Furthermore, using a selection of patient-reported outcomes opens up the possibility of further investigations to assess the detailed biopsychosocial model and to model the direct and indirect effects of impairments and activity limitations on participation (particularly work) and QoL. Although there are several new QoL scales for stroke, and some which have been validated for SAH, these invariably belong to the HRQoL tradition, effectively measuring health status within the impairment-activity limitation-participation domains. ${ }^{50}$ While use of these as QoL instruments effectively precludes investigation of the impact of function on QoL, nevertheless, such scales may provide good diseasespecific measures of health status to include in a more comprehensive model, replacing generic measures such as the BI.

In conclusion, the current study has shown that a selection of patient-reported outcomes have validity for ASAH, and can deliver a broad range of information, suitable for clinical management and research purposes. It has emphasised the impact of cognitive impairment and shown that traditional outcome measures such as the Modified Rankin Scale do not tell the full story. As such, the current study contributes to the identification of the need for clinical services following ASAH, as well as the identification of a potential core set of PROMs for ASAH.

\section{Author affiliations}

${ }^{1}$ Department of Anaesthesia, Leeds General Infirmary, Leeds, UK

${ }^{2}$ Walton Centre for Neurology and Neurosurgery, Liverpool, UK

${ }^{3}$ Department of Neuro-surgery, Hope Hospital, Salford, Manchester, UK

${ }^{4}$ Department of Neurosurgery, Leeds General Infirmary, Leeds, UK

${ }^{5}$ Faculty of Medicine and Health, Leeds Institute of Rheumatic and Musculoskeletal Medicine (LIRMM), University of Leeds, Leeds, UK

Contributors All the authors have made substantial contributions to conception and design, acquisition of data, or analysis and interpretation of data; drafted the article or revised it critically for important intellectual content; and been involved in the final approval of the version to be published.

Funding This research received no specific grant from any funding agency in the public, commercial or not-for-profit sectors.

\section{Competing interests None.}

Ethics approval The study was approved by the West and Central Yorkshire Ethics Committee (Ref 08/H1313/95).

Provenance and peer review Not commissioned; externally peer reviewed.

Data sharing statement No additional data are available.

Open Access This is an Open Access article distributed in accordance with the Creative Commons Attribution Non Commercial (CC BY-NC 3.0) license, which permits others to distribute, remix, adapt, build upon this work noncommercially, and license their derivative works on different terms, provided the original work is properly cited and the use is non-commercial. See: http:// creativecommons.org/licenses/by-nc/3.0/ 


\section{REFERENCES}

1. Sandvei MS, Mathiesen EB, Vatten LJ, et al. Incidence and mortality of aneurysmal subarachnoid hemorrhage in two Norwegian cohorts, 1984-2007. Neurology 2011;77:1833-9.

2. Longstreth WT Jr, Nelson LM, Koepsell TD, et al. Clinical course of spontaneous subarachnoid hemorrhage: a population-based study in King County, Washington. Neurology 1993;43:712-18.

3. Kreiter KT, Copeland D, Bernardini GL, et al. Predictors of cognitive dysfunction after subarachnoid hemorrhage. Stroke 2002;33:200-8.

4. Al-Khindi T, Macdonald RL, Schweizer TA. Cognitive and functional outcome after aneurysmal subarachnoid hemorrhage. Stroke 2010;41:e519-36.

5. Passier PECA, Visser-Meily JMA, Rinkel GJE, et al. Life satisfaction and return to work after aneurysmal subarachnoid hemorrhage. J Stroke Cerebrovasc Dis 2011;20:324-9.

6. Molyneux A, Kerr R, Stratton I, et al. International Subarachnoid Aneurysm Trial (ISAT) of neurosurgical clipping versus endovascular coiling in 2143 patients with ruptured intracranial aneurysms: a randomised trial. Lancet 2002;360:1267-74.

7. Jennett $B$, Bond $M$. Assessment of outcome after severe brain damage. Lancet 1975;1:480-4.

8. Jennett B, Snoek J, Bond MR, et al. Disability after severe head injury: observations on the use of the Glasgow Outcome Scale. J Neurol Neurosurg Psychiatry 1981;44:285-93.

9. Farrell B, Godwin J, Richards S, et al. The United Kingdom transient ischaemic attack (UK-TIA) aspirin trial: final results. J Neurol Neurosurg Psychiatry 1991;54:1044-54.

10. Kim DH, Haney CL, Van Ginhoven G. Utility of outcome measures after treatment for intracranial aneurysms: a prospective trial involving 520 patients. Stroke 2005;36:792-6.

11. Lees KR, Bath PMW, Schellinger PD, et al. Contemporary outcome measures in acute stroke research. Choice of primary outcome measure. Stroke 2012;43:1163-70.

12. Hutter BO, Gilsbach JM. Which neuropsychological deficits are hidden behind a good outcome (Glasgow=I) after aneurysmal subarachnoid hemorrhage? Neurosurgery 1993;33:999-1005. discussion 1005-1006.

13. Passier PRCA, Visser-Meily JMA, van Zandvoort MJE, et al. Prevalence and determinants of cognitive complaints after aneurysmal subarachnoid hemorrhage. Cerebrovasc Dis 2010;29:557-63.

14. Stienen MN, Weisshaupt R, Fandino J, et al. Swiss SOS study group. Current practice in neuropsychological outcome reporting after aneurysmal subarachnoid haemorrhage. Acta Neurochir (Wien) 2013;155:2045-51.

15. Rinkel GJE, Algra A. Long-term outcomes of patients with aneurysmal subarachnoid haemorrhage. Lancet Neurol 2011;10:349-56.

16. Kapapa T, Woischneck D, Tjahjadi M. Long-term health-related quality of life after spontaneous nontraumatic subarachnoid hemorrhage: self and proxy reports in a 10-year period. World Neurosurg 2012;pii:S1878-8750.

17. Krajewski K, Dombek S, Martens T, et al. Neuropsychological assessments in patients with aneurysmal subarachnoid hemorrhage perimesencephalic SAH, and incidental aneurysms. Neurosurg Rev 2014;37:55-62.

18. World Health Organisation. International Classification of Impairments, Disabilities and Handicaps (ICIDH). Geneva: World Health Organization, 1980.

19. World Health Organization. International Classification of Functioning, Disability and Health (ICF). Geneva: World Health Organization, 2001

20. Wilson IB, Cleary PD. Linking clinical variables with health-related quality of life. A conceptual model of patient outcomes. JAMA 1995;273:59-65.

21. Tennant A. Quality of life: a measure to far? Ann Rheum Dis 1995:54:439-40

22. Bent N, Tennant A, Swift T, et al. Ad hoc or focussed services for young people with physical disabilities? Lancet 2002;360:1280-6.

23. Gomertz P, Pund P, Ebrahim S. A postal version of the Barthel Index. Clin Rehabil 1994;8:233-9.

24. Norris G, Tate RL. The behavioural assessment of the dysexecutive syndrome (BADS): ecological, concurrent and construct validity. Neuropsychol Rehabil 2000;10:33-45.
25. Gerstorf D, Siedlecki KL, Tucker-Drob EM, et al. Executive dysfunctions across adulthood: measurement properties and correlates of the DEX self-report questionnaire. Neuropsychol Dev Cogn B Aging Neuropsychol Cogn 2008;15:424-45.

26. Pedrero-Pérez EJ, Ruiz-Sánchez de León JM, Lozoya-Delgado P, et al. [Prefrontal symptoms assessment: psychometric properties and normative data of the Dysexecutive questionnaire (DEX) in a sample from the Spanish population]. Rev Neurol 2011;52:394-404. [Article in Spanish]

27. Sunderland A, Harris JE, Baddeley AD. Do laboratory tests predict everyday memory? A neuropsychological study. J Verbal Learn Verbal Behav 1983;22:727-38.

28. Sunderland A, Harris JE, Gleave J. Memory failures in everyday life following severe head injury. J Clin Neuropsychol 1984;6:127-42.

29. Coughlan AK, Storey P. The Wimbledon Self Report Scale: emotional and mood appraisal. Clin Rehabil 1988;2:207-13.

30. Barker S, Kent RM, Tennant A. Quality of life after stroke: the development of a needs based quality of life scale, the stroke-QoL. Clin Rehabil 2007;22:667.

31. Wainer H, Kiely $\mathrm{G}$. Item clusters and computer adaptive testing: a case for testlets. J Educ Meas 1987;24:185-202.

32. Andrich D, Lyne A, Sheridan B, et al. RUMM 2030. Perth: RUMM Laboratory, 2009.

33. Masters G. A Rasch model for partial credit scoring. Psychometrika 1982;47:149-74.

34. Tennant A, Conaghan PG. The Rasch measurement model in rheumatology: what is it and why use it? When should it be applied, and what should one look for in a Rasch paper? Arthritis Rheum 2007;57:1358-62.

35. da Rocha NS, Chachamovich E, de Almeida Fleck MP, et al. An introduction to Rasch analysis for psychiatric practice and research. $J$ Psychiatr Res 2013;47:141-8.

36. Christiensen KB, Kreiner S, Mesbah M. Rasch models in health. London: J Wiley \& sons, 2013.

37. Fertl E, Killer M, Eder H, et al. Long-term functional effects of aneurysmal haemorrhage with special emphasis on the patient's view. Acta Neurochir (Wien) 1999;141:571-7.

38. Bellebaum C, Schafers L, Schoch B, et al. Clipping versus coiling: neuropsychological follow up after aneurysmal subarachnoid haemorrhage (SAH). J Clin Exp Neuropsychol 2004;26:1081-92.

39. Bowen A, Neumann V, Conner M, et al. Mood disorders following traumatic brain injury: identifying the extent of the problem and the people at risk. Brain Inj 1998;12:177-90.

40. Bowen A, Chamberlain MA, Tennant A et al. The persistence of mood disorders following traumatic brain injury: a 1 year follow-up. Brain Inj 1999;13:547-53.

41. Vetkas A, Lepik T, Eilat T, et al. Emotional health and quality of life after aneurysmal subarachnoid hemorrhage. Acta Neurochir (Wien) 2013;155:1107-14

42. Kreiter KT, Rosengart AJ, Claassen J, et al. Depressed mood and quality of life after subarachnoid hemorrhage. J Neurol Sci 2013;335:64-71.

43. Visser-Meily JM, Rinkel GJ, Vergouwen MD, et al. Post-traumatic stress disorder in patients 3 years after aneurysmal subarachnoid haemorrhage. Cerebrovasc Dis 2013;36:126-30.

44. McKenna SP, Doward LC. The needs-based approach to quality of life assessment. Value Health 2004;7(Suppl 1):S1-3.

45. Wilburn J, McKenna SP, Perry-Hinsley D, et al. The impact of Dupuytren disease on patient activity and quality of life. $J$ Hand Surg Am 2013;38:1209-14.

46. Diener E. Subjective well-being. Psychol Bull 1984;95:542-75.

47. Hackett ML, Anderson CS. Health outcomes 1 year after subarachnoid hemorrhage: an international population-based study. The Australian Cooperative Research on Subarachnoid Hemorrhage Study Group. Neurology 2000;55:658-62.

48. Hellawell DJ, Taylor R, Pentland B. Persisting symptoms and carers' views of outcome after subarachnoid haemorrhage. Clin Rehabil 1999;13:333-40.

49. Hop JW, Rinkel GJ, Algra A, et al. Quality of life in patients and partners after aneurysmal subarachnoid hemorrhage. Stroke 1998;29:798-804.

50. Wong GK, Lam SW, Ngai K, et al. Quality of Life after Brain Injury (QOLIBRI) Overall Scale for patients after aneurysmal subarachnoid hemorrhage. J Clin Neurosci 2013 pii: S0967-5868(13)00603-6. doi:10.1016/j.jocn.2013.09.010. [Epub ahead of print] 